\title{
Técnicas e sítios de coleta de medula óssea em cães e gatos
}

\author{
Techniques and bone marrow sites sampling in dogs and cats
}

\author{
Daniel Curvello de Mendonça Müller ${ }^{I *}$ Ney Luis Pippi ${ }^{I I}$ Paula Cristina Basso ${ }^{I}$ \\ Debora Cristina Olsson ${ }^{\mathrm{III}}$ Eduardo de Bastos Santos Junior ${ }^{\mathrm{I}}$ \\ Antônio Cezar Oliveira Guerra ${ }^{\mathrm{IV}}$
}

\section{- REVISÃO BIBLIOGRÁFICA -}

\section{RESUMO}

Atualmente, o incremento das pesquisas enfoca a medula óssea como fonte potencial para o tratamento de doenças, uma vez que seu uso como diagnóstico já é largamente empregado. Os objetivos deste artigo são revisar os melhores acessos à medula óssea e destacar a importância desse material como diagnóstico e tratamento de doenças. São abordadas particularidades sobre as técnicas de coleta e as complicações observadas pelos autores, a fim de facilitar os procedimentos, tornando-os mais seguros.

Palavras-chave: cães, gatos, biópsia, medula óssea, punção biópsia aspirativa.

\section{ABSTRACT}

Currently, the research focuses on bone marrow as a potential source for the treatment of diseases, since its use as a diagnosis is already largely employed. This paper aims to promote a practical review on the best access to the bone marrow and the importance of this material as diagnosis and treatment. Sampling techniques are observed and detailed by the authors, in order to facilitate the procedures and make them safer.

Key words: dogs, cats, biopsy, bone marrow, aspiration citology.

\section{INTRODUÇÃO}

A medula óssea tem como principal função a hematopoeise de células eritróides, granulocíticas, megacariocíticas e linfocitárias. Nos animais em crescimento, a hematopoese ocorre no interior dos ossos longos e chatos. À medida que o animal envelhece, a região do canal medular é substituída por tecido adiposo, confinando a medula ativa nos locais onde há osso esponjoso, ou seja, epífises e metáfises ósseas (RASKIN, 1998).

A coleta de medula óssea é indicada visando o diagnóstico (DOMINIS et al., 2005) e a obtenção de células pluripotenciais para o tratamento de doenças (SILVA \& MACEDO, 2006). De posse dessa amostra de medula óssea, é possível realizar diversos exames, como o mielograma, a partir da preparação em lâmina, a citometria de fluxo, a imunohistoquímica e, ainda, a citogenética convencional. Dessa forma, a avaliação ideal da celularidade medular requer a integração das informações obtidas, tanto do aspirado, quanto da biópsia, à luz dos achados da avaliação do sangue periférico (FLEURY, 2007). Células-tronco, obtidas a partir de aspirados de medula óssea, são utilizadas em

\footnotetext{
IPrograma de Pós-graduação em Medicina Veterinária, Universidade Federal de Santa Maria (UFSM), 97105-900, Santa Maria, RS, Brasil. E-mail: cmdaniel@terra.com.br. *Autor para correspondência.

IIDepartamento de Clínica de Pequenos Animais (DCPA), UFSM, Santa Maria, RS, Brasil.

III Hospital de Clínica Veterinária, Universidade do Estado de Santa Catarina (UDESC), Lages, PR, Brasil.

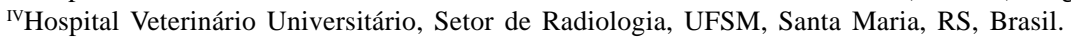


pacientes portadores de leucemia. Esse uso é cada vez mais explorado como terapia celular de recomposição da celularidade medular e do sangue periférico. Essas novas técnicas estão sendo aplicadas em um amplo espectro de doenças humanas, incluindo muitos tipos de câncer, doenças neurológicas, como Parkinson, diabetes e doenças cardíacas (AZEVEDO \& RIBEIRO, 2000; SILVEIRA et al., 2005).

Em medicina veterinária, as pesquisas envolvendo transplante de células-tronco hematopoiéticas vêm crescendo (OLIVEIRA, 2008; TOGNOLI et al., 2009). ZAMPROGNO (2007) demonstrou que a terapia autóloga com células-tronco provenientes da medula óssea mostrou-se efetiva para a estimulação osteogênica de não união de fraturas. BRUNELLI et al., (2007) avaliaram os efeitos do transplante de células-tronco autógenas do limbo esclerocórneo de cães sobre lesões córneo-limbais. Constataram que a vantagem do transplante está em possibilitar a melhoria da transparência córnea, sem intercorrências oculares.

Contudo, para a obtenção de células hematopoiéticas, é necessária a sua coleta e, para tanto, a aspiração intraóssea da medula, utilizando-se agulhas específicas em locais onde se obtém maior abundância desse material. Geralmente, as punções ocorrem na crista ilíaca, no trocanter maior do fêmur, na área transilíaca e na região epifisária proximal do úmero. O material deve ser coletado em condições assépticas, com o paciente sob anestesia geral, e devem ser utilizadas seringas contendo anticoagulantes para realizar a sucção da medula óssea (RASKIN, 1998).

O objetivo deste artigo é realizar uma revisão sobre as técnicas e complicações durante a obtenção de medula óssea, abordando a importância do material coletado, os equipamentos utilizados habitualmente para essa coleta, bem como as principais vias de acesso, conforme a espécie do animal.

Indicações de coleta da medula óssea

Normalmente a coleta de medula óssea (MO) é conduzida visando a obtenção de fragmentos para realização de mielograma, indicado em situações bem precisas. Este consiste no exame direto das células da MO, colhidas por punção aspirativa, e permite verificar a normalidade da produção sanguínea, as alterações no aspecto celular e a presença de células neoplásicas (AQUINO et al., 2002). Geralmente é solicitado quando se encontram alterações no hemograma (GOSSET, 2000), tais como neutropenia persistente, trombocitopenia, leucocitose, morfologia anormal de células sanguíneas, presença inexplicável de células imaturas no sangue, anemia arregenerativa ou ainda uma combinação dessas enfermidades (GALE et al., 1981). Também pode ser usado após um quadro de hiperproteinemia, quando há suspeita de mieloma múltiplo, alguns casos de linfoma, leishmaniose, brucelose, erliquiose e doenças sistêmicas de origem fúngica, entre outras (AQUINO et al., 2002). Pode-se ainda indicar a causa de hipercalcemia quando associada com neoplasmas (OLIVEIRA, 2008).

SOBRINHO et al., (1979) conduziram mielogramas em 22 crianças portadoras de má nutrição protéica (MNP) e puderam observar hiperplasia de série branca e sinais de deficiência de fatores de maturação expressos pela presença de macrocitose e macronormoblastose na quase totalidade das crianças. Observaram, ainda, ausência ou escassez de depósitos de ferro em 17 casos (77\%).

O mielograma é indispensável, por exemplo, para o diagnóstico e a classificação das leucemias mielóides e linfóides agudas. Nessa doença, um grande número de células tumorais, chamadas blastos, é encontrado no interior da MO (LUND, 2000).

Diferentemente do exame anterior, que consiste em examinar as células medulares a partir de uma preparação citoscópica, a biópsia de MO (BMO) permite avaliar também toda a sua estrutura, pois ela é feita a partir de um fragmento compacto de osso. Tal procedimento é utilizado na prática médica, principalmente para o diagnóstico de doenças hematológicas ou metastáticas (AQUINO et al., 2002). Praticamente não existe contra-indicação, sendo esse procedimento realizado inclusive em animais portadores de doenças hemorrágicas sem observação de maiores danos (JAIN, 1993).

Embora a aspiração de MO seja um procedimento menos traumático do que a BMO, esta última fornece dados importantes como o grau de celularidade medular e o diagnóstico de enfermidades como mielofibrose, mieloesclerose e focos de infecção, além de avaliar a quantidade de gordura presente no interior da medula (LUND, 2000). WIJEWARDANA et al., (2007) isolaram e caracterizaram células progenitoras da medula óssea de cães com diagnóstico de leucemia ou linfoma malígno.

Outra indicação da coleta de medula óssea por aspiração é o transplante de células da MO e o cultivo celular para aquisição de células mononucleares, células-tronco hematopoiéticas ou células-tronco mesenquimais (TOGNOLI et al., 2009). As célulastronco (CT) são tipos especiais de células, que estão presentes principalmente nos embriões (CT embrionárias), no cordão umbilical, no fígado fetal e na medula óssea (CT adultas) (SILVEIRA et al., 2005). Em cães, a presença de células-tronco hematopoiéticas tem

Ciência Rural, v.39, n.7, out, 2009. 
sido observada na medula óssea (BRUNO et al., 2001; NAKAGE et al., 2005) e no sangue do cordão umbilical (NAKAGE \& SANTANA, 2006). Vários estudos demonstraram a grande plasticidade dessas células adultas ao se diferenciarem em músculo esquelético, osso, cartilagem, gordura e fígado, o que se torna uma esperança para o tratamento de diversas doenças. Essas células apresentam também um vasto potencial na terapia de doenças cardíacas (SILVEIRA et al., 2005).

\section{Agulhas de coleta}

Em 1929, utilizou-se pela primeira vez a punção aspirativa da medula óssea para o estudo citológico sistemático, propiciando o reconhecimento e a descrição das células precursoras (CURY, 2003). Três décadas mais tarde, Macfarland relatou as vantagens da retirada de um fragmento ósseo, utilizando a agulha de Silverman. Com esse método, obtinha-se uma maior quantidade de material medular, o que possibilitava maior número de cortes e de colorações histológicas. Em 1971, Jamshidi criou uma nova agulha para a realização de BMO, a qual apresentava a vantagem de ser menos traumática e mais confortável ao manuseio (CURY, 2003). A agulha original de Jamshidi foi modificada por Inwood alguns anos depois, a fim de melhorar a obtenção do material celular (CURY, 2003).

Desde então, existem diversas agulhas para uso clínico, de diversas procedências (RASKIN, 1998). Tais agulhas servem, tanto para a administração de diversos produtos sanguíneos, soluções e agentes farmacológicos em situações de urgência, quanto para coleta de material para exames cito e histopatológicos e transplantes (JUNIOR et al., 2008). Os autores desta revisão sugerem como equipamentos de eleição para infusões intraósseas as agulhas de Jamshidi ou agulhas de mielograma. Por meio destas, pode-se acoplar um equipo e administrar soluções, considerando que estudos demonstram que substâncias injetadas na medula óssea são distribuídas imediatamente na circulação sistêmica (JUNIOR et al., 2008).

Quando é necessária uma quantidade elevada de medula óssea, sugere-se a utilização de agulhas com o calibre maior do que as citadas anteriormente, a fim de aumentar o volume coletado (OLIVEIRA, 2008; TOGNOLI et al., 2009) em menor tempo cirúrgico. Situações assim são requeridas nas coletas visando à obtenção de células para transplantes de medula óssea nos casos de pacientes oncohematológicos e transplantes de células-tronco obtidas do isolamento da fração total colhida, o que difere dos cultivos celulares, que requerem uma quantidade menor de células da medula óssea. No isolamento, a quantidade de medula óssea a ser colhida é maior, pois nesse material deverá conter o número de células suficientes para o transplante. Esse número é de aproximadamente $10^{6}$ células. Para tanto, podem ser utilizadas as agulhas de Osgood diâmetro $30 \times 12$ (LOPES et al., 1998), a agulha de Steiss (OLIVEIRA, 2008; TOGNOLI et al., 2009), a agulha de Rosenthal (RASKIN, 1998) ou a agulha Jamshidi (SAMOTO, 2006; ZAMPROGNO, 2007). Além disso, CASTANIA(2007) utilizou agulha hipodérmica do tamanho 40 x 12mm para obtenção de pequena quantidade de medula óssea.

Em pesquisas realizadas pelos autores, utilizou-se a agulha de Steiss na coleta de medula óssea em gatos (Figura 1) e cães (Figuras 2 e 3),

assim como nos trabalhos de (OLIVEIRA, 2008; TOGNOLI et al., 2009), e obteve-se o volume desejado de MO para transplante autólogo, em tempos de coleta de 18,4 minutos $\pm 4,21$. Apesar de a agulha utilizada apresentar diâmetro aparentemente elevado em relação ao osso, como visto nas figuras 1, 2 e 3, sabe-se, por meio dos princípios de estabilização de fraturas, que o canal medular pode ser preenchido em 60 a $70 \%$ com pinos de Steinmann, sem que isso acarrete prejuízo vascular do córtex ósseo (EL-WARRAK \& SCHOSSLER, 1998). Sendo assim, os autores desta revisão adotam esse parâmetro para a determinação do tamanho da agulha em relação ao tamanho do osso. Para tanto, certifica-se, por meio do estudo radiográfico (Figura 1), que a agulha não preencherá mais do que $70 \%$ do canal medular ósseo, evitando danos vasculares.

Principais vias de acesso para coleta de células medulares hematopoiéticas

Em cães e gatos, a medula óssea pode ser obtida na epífise dos ossos longos e nas regiões do íleo, como crista ilíaca ou borda acetabular (Figura 1A, 3D,3E, 3F). RASKIN (1998) sugere a coleta na crista ilíaca de cães, pela facilidade de localização. Diversos autores utilizaram a referida via de acesso para coleta de medula óssea, tanto para obtenção de células mononucleares, quanto para aquisição de células medulares, em exames cito-histopatológicos (HANS et al., 2005; SAMOTO, 2006; VAZ, 2006; CASTANIA, 2007; ZAMPROGNO, 2007; SALGADO, 2008). Contudo, em cães de pequeno porte ou gatos, a coleta de amostras medulares é facilitada na região trans-ilíaca ou porção proximal do fêmur (Figura 1B, 2). Punções trans-ilíacas reduzem o risco de lesões provocadas pelo deslizamento acidental da agulha pela crista ilíaca (RASKIN, 1998). MASSUMOTO et al. (1997) colheram M.O. do osso esternal e do íleo de pessoas e não relataram complicações decorrentes dessa técnica. No 


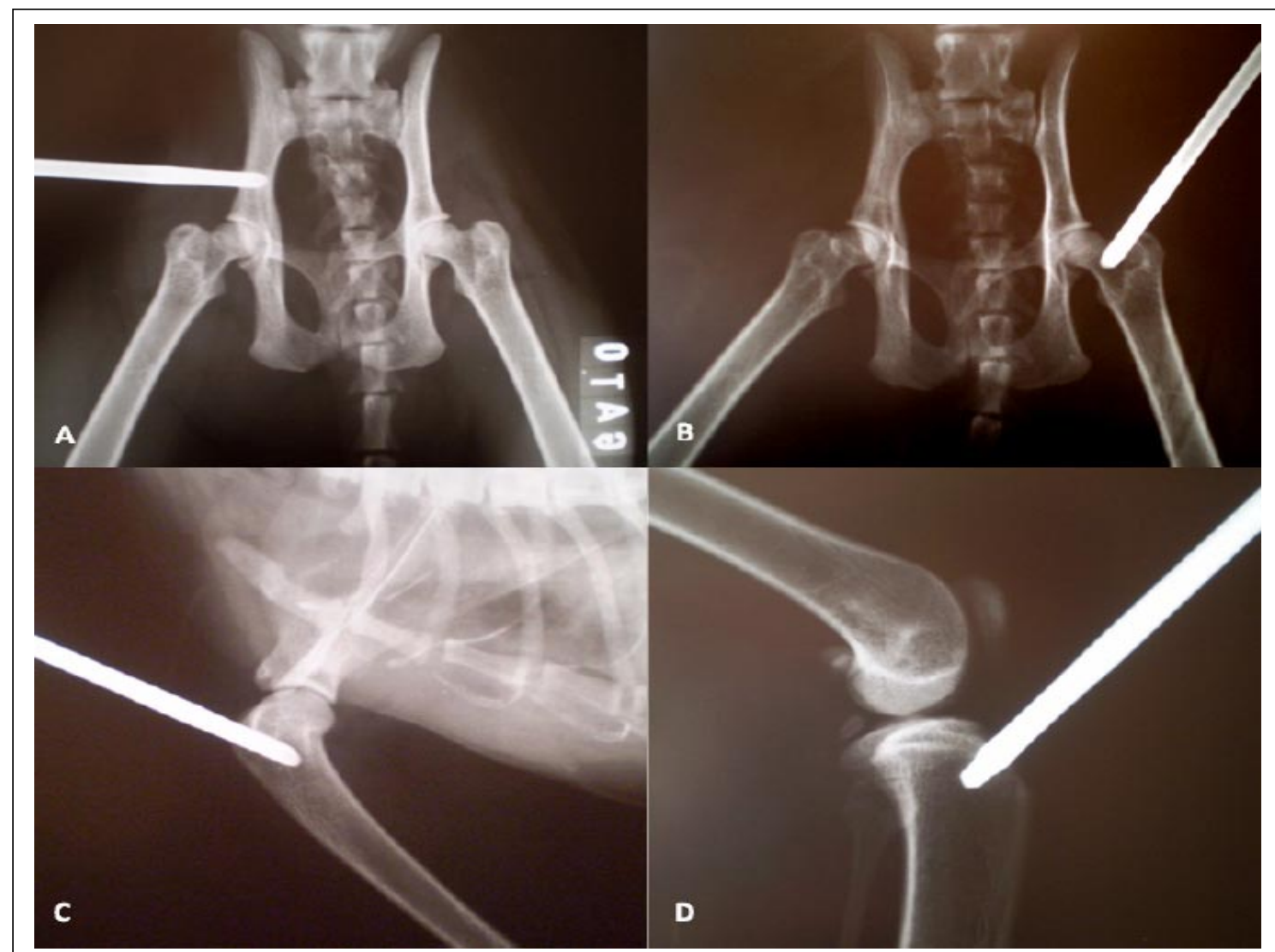

Figura 1 - Obtenção de medula óssea com agulha de Steiss em felino. (A) Imagem radiográfica ventro-dorsal da agulha introduzida no corpo do íleo; (B) Imagem da ventro-dorsal da agulha no trocanter maior do fêmur; (C) Imagem radiogáfica antero-posterior da agulha de Steis introduzida no tuberculo maior do úmero; (D) Imagem lateral da região epifisária proximal da tíbia.

entanto, descreveram que a obtenção do volume de $10-15 \mathrm{~mL} \mathrm{~kg}^{-1}$ (de peso do paciente) de medula ocorreu somente após múltiplas perfurações.

Para cães obesos ou musculosos, a porção crânio-lateral da tuberosidade maior do úmero (Figura 1C, 3G, 3H, 3I) é uma ótima opção para coleta de material (RASKIN, 1998; ZAMPROGNO, 2007). Os autores desta revisão sugerem também a epífise proximal da tíbia (Figura 1D, 3A, 3B, 3C) como sendo uma região para obtenção de grande quantidade de medula óssea, assim como a porção proximal do fêmur e a tuberosidade maior do úmero, citadas anteriormente.

\section{Técnicas de coleta}

Para o procedimento de coleta em razão do exame cito-histopatológico ou da obtenção de células progenitoras da MO de cães, o animal deverá ser submetido à anestesia geral. O período pré-operatório deverá incluir jejum alimentar de 12 horas e restrição hídrica de seis horas, sendo realizada previamente a tricotomia do sítio de coleta (VAZ, 2006; CASTANIA,
2007; ZAMPROGNO, 2007; SALGADO, 2008). O paciente deve ser anestesiado e posicionado conforme o local escolhido para a coleta. Sugere-se o decúbito lateral (MENDONÇA et al., 2003; CASTANIA, 2007; ZAMPROGNO, 2007) se a coleta da medula óssea for realizada no osso femoral ou tibial, e o decúbito ventral se a escolha for a crista ilíaca (OLIVEIRA, 2008; TOGNOLI et al., 2009). Entretanto, na prática dos autores, prefere-se o decúbito lateral, pois com esse posicionamento é possível acessar todos os locais anatômicos sugeridos anteriormente.

A precisão dos movimentos de introdução da agulha no canal medular pode determinar a rapidez e a precisão do procedimento, garante os autores. Estes sugerem a seguir algumas manobras que promovem a eficiência do procedimento. A empunhadura da agulha deve ser bem apoiada na palma da mão, para que o cirurgião consiga aplicar melhor a sua força. O dedo indicador deve ser colocado na porção final da agulha, ou seja, a cerca de $4 \mathrm{~cm}$ do bisel, e será o responsável, tanto pelo movimento de pivô da mão do cirurgião, 


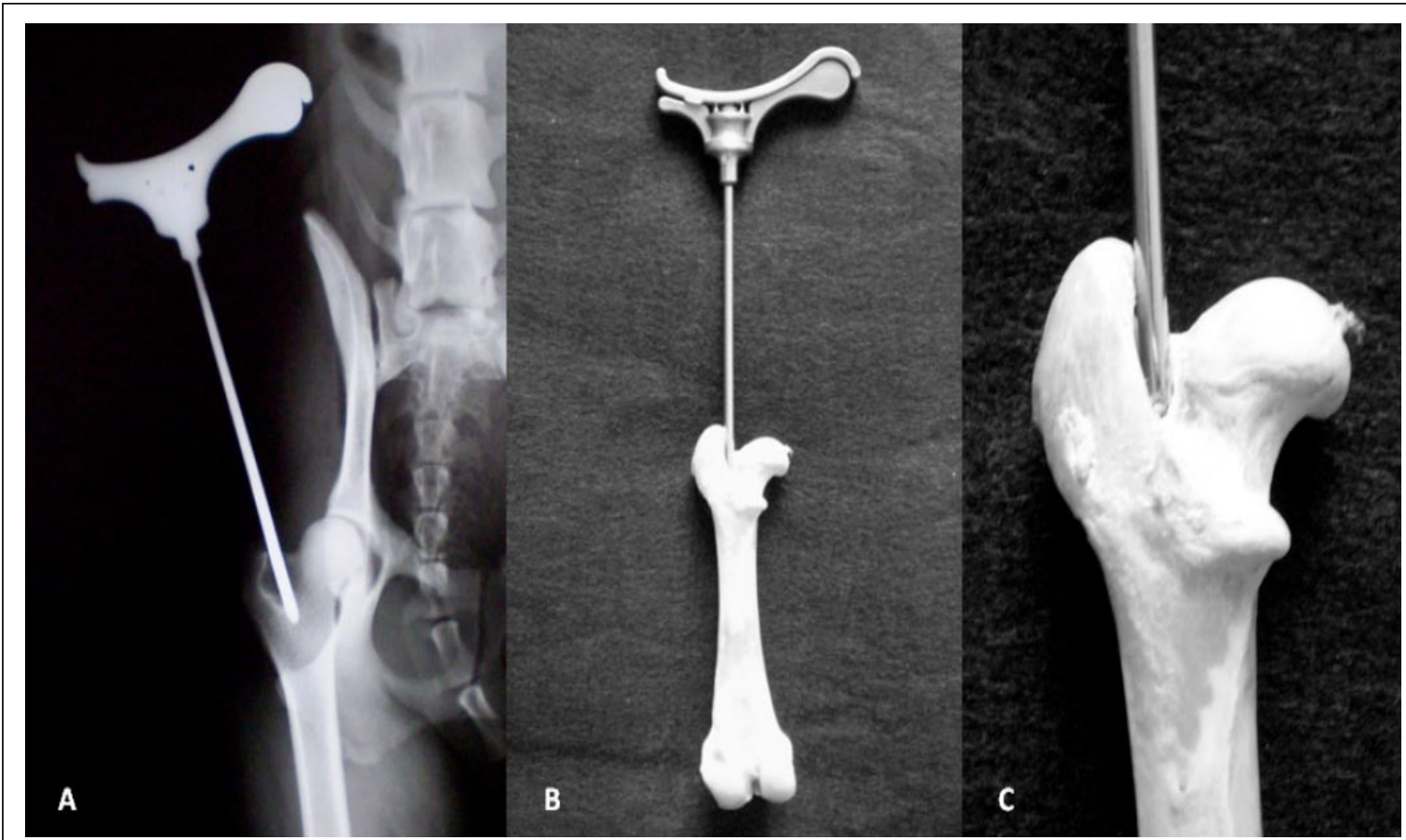

Figura 2 - Punção da fossa trocantérica de cão com agulhas Steiss. (A) Imagem radiográfica ventro-dorsal; (B, C) Detalhes do local de introdução da agulha no osso. Observa-se que a extremidade da agulha é apoiada contra a face interna do trocanter maior do fêmur.

direcionando a perfuração e introdução da agulha, quanto pela limitação da introdução desta. Essa limitação é importante, pois assegura que somente a porção adiante do dedo seja introduzida. Esse artifício oferece certo grau de segurança ao procedimento, uma vez que limita eventuais perfurações indesejadas, caso haja deslizamento da agulha.

A outra mão será utilizada para apreender e delimitar as extremidades do local a ser perfurado, garantindo, assim, que a agulha seja introduzida na região desejada do osso. Para iniciar a perfuração, devem ser realizados movimentos de rotação com a mão (OLSSON et al., 2006), o pulso e o antebraço, simultaneamente, evitando a movimentação lateral da agulha. O cotovelo e o braço do cirurgião deverão permanecer imóveis, para garantir que o orifício de entrada da agulha seja o menor possível. Atenta-se ainda para que os movimentos de rotação sejam lentos e de grande amplitude, pois, assim, aproveita-se melhor a superfície de corte da extremidade do bisel.

Os autores desde artigo recomendam que todas as agulhas citadas anteriormente sejam utilizadas com um mandril em seu interior, concordando com LARUE et al., (2005), os quais sugerem tal procedimento quando for utilizada a agulha Jamshidi. Isso evita a obstrução da sua luz por esquírolas ósseas. Após a introdução e estabilização da agulha, o mandril deve ser removido, e uma seringa de $10 \mathrm{~mL}$ contendo anticoagulante deve ser acoplada. Discreta retração do êmbolo é suficiente para obtenção de vácuo e aquisição do material desejado. A amostra coletada deve ser encaminhada ao laboratório em seringa previamente anticoagulada, em temperatura ambiente, ou ainda podem ser confeccionadas as lâminas, a partir de MO in natura, para serem analisadas tão logo obtidas (OLSSON et al., 2006).

\section{Complicações}

Algumas complicações eventualmente poderão ocorrer durante a coleta de medula óssea nos ossos longos, dentre elas, as fraturas (LAREU et al., 2005). Estas se tornam iminentes quando são realizados movimentos de "alavanca" com a agulha, gerando força de separação dos fragmentos ósseos, conforme experiência dos autores. Estes afirmam que essa situação é evitada toda vez que o cotovelo e o braço do cirurgião permanecem imóveis, deixando a rotação exclusivamente para a mão, o punho e o antebraço. Contudo, alertam que fraturas podem ocorrer quando são realizadas múltiplas perfurações em uma mesma região do osso. Isso é evitado quando as sessões de biópsia aspirativa são feitas em ossos distintos. 


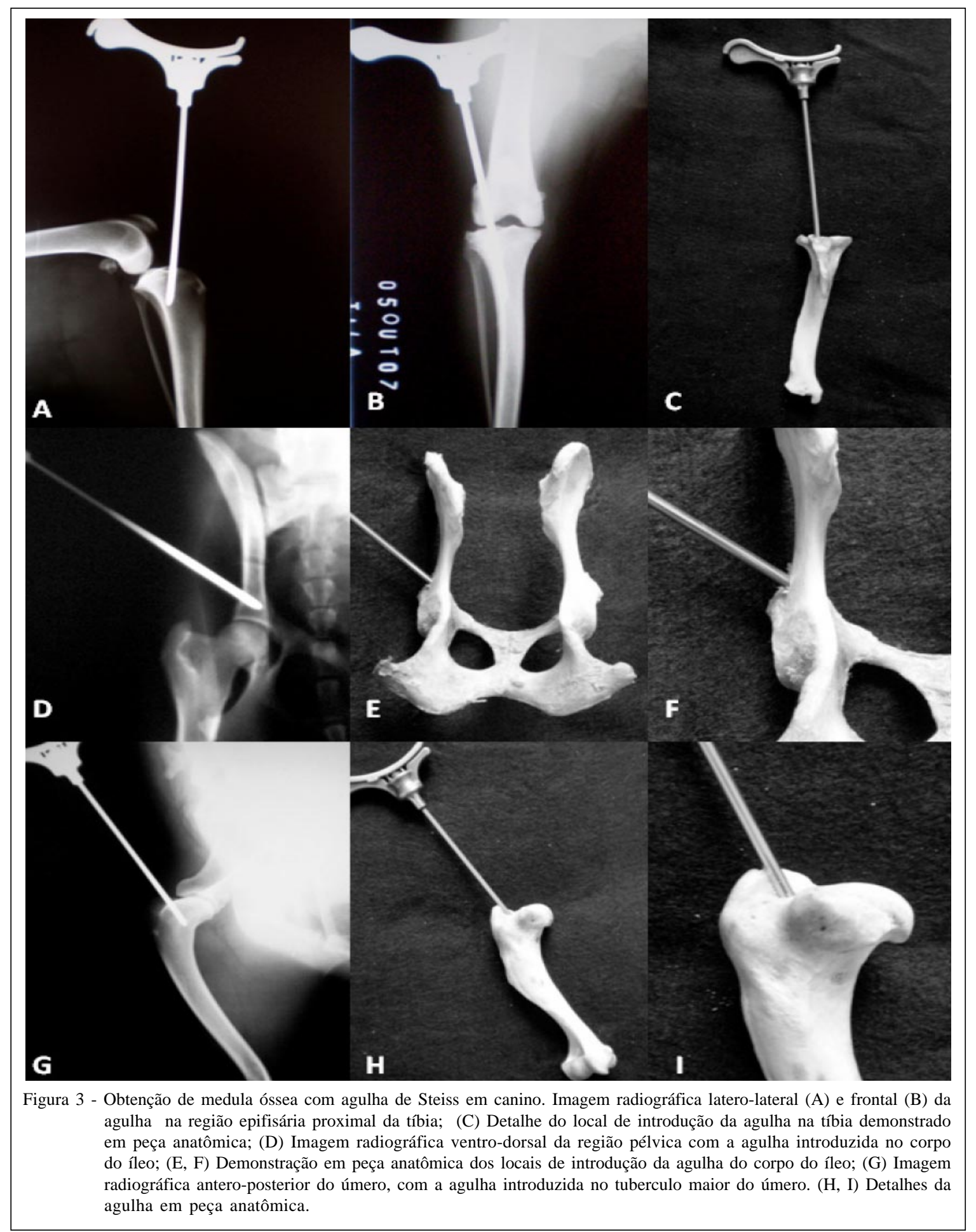

Em ossos da pelve, alguns acidentes importantes poderão ocorrer caso não haja o cuidado de delimitar a agulha com o dedo indicador, conforme sugerido anteriormente pelos autores. Essa região se apresenta como uma "caixa”, envolvendo as vísceras pélvicas (TARVIN \& LENEHAN, 2005). Caso haja o deslizamento da agulha através do osso, como sugerido por RASKIN (1998), a extremidade cortante da agulha poderá ser projetada para o interior da pelve (Figura 4A, 4B), perfurando uma víscera, como reto ou próstata,

Ciência Rural, v.39, n.7, out, 2009. 


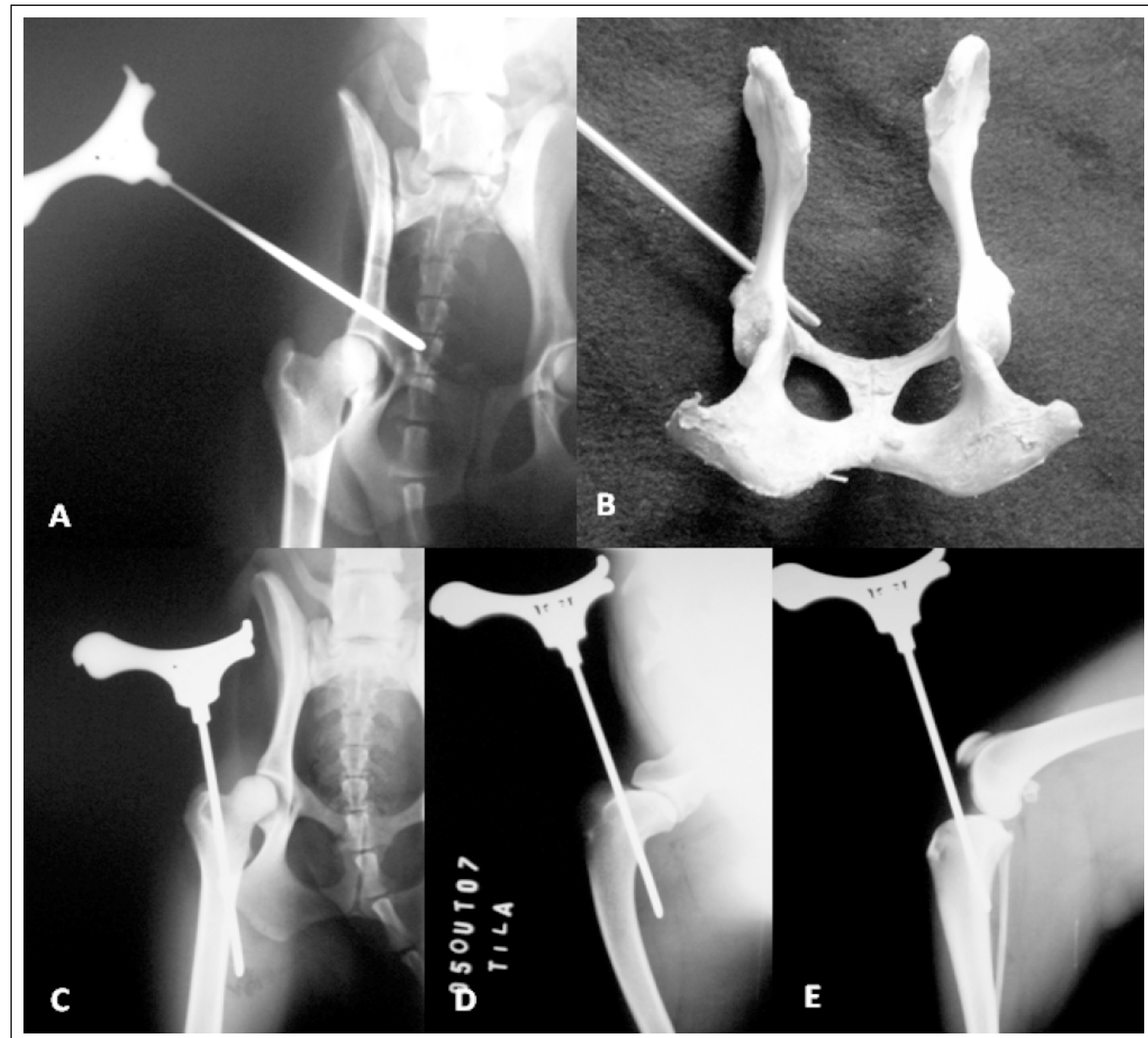

Figura 4 - Imagens radiográficas de complicações durante a coleta de medula óssea. (A) Imagem ântero-posterior da pelve, com a agulha de Steis transpassando o corpo do íleo e penetrando o interior da pelve. (B) Detalhe na peça anatômica, demonstrando a extremidade da agulha dentro da pelve e simulando as situações onde se transpassam as duas corticais do corpo do íleo. (C) Imagem ântero-posterior, demonstrando a agulha introduzida no trocanter maior do fêmur e emergindo na região medial da coxa. (D) Imagem da agulha transpassando o tubérculo maior do úmero. (F) Imagem radiográfica da agulha transpassando a cortical oposta da região proximal da tíbia.

ou um grande vaso, provocando hemorragia local. Essa situação certamente é uma emergência, que poderia colocar em risco a vida do paciente.

Nas complicações desse procedimento, incluem-se os danos às estruturas de tecidos moles (LAREU et al., 2005) e a ausência de medula óssea durante a aspiração. Neste último caso, deve-se ter o cuidado de aspirar várias vezes o local puncionado com uma seringa de 10 ou $20 \mathrm{~mL}$, para que promova vácuo suficiente, antes de afirmar que a agulha não está no local correto. Permanecendo o insucesso de aspirado de MO, a perfuração poderá ter ultrapassado a cortical do osso (Figura 4) e, assim, a abertura da agulha não estará no canal medular. Os autores desta revisão sugerem que, caso a suspeita seja esta, basta reintroduzir o mandril da agulha e recuá-la lentamente até que comece a refluir o sangue medular.

Existe ainda o risco de contaminação do canal medular, que pode evoluir para osteomielite. Cabe lembrar que, mesmo tratando-se de um pequeno orifício, este se constitui numa porta de entrada de patógenos, sendo fundamental a realização de minuciosa antissepsia pré e pós-operatória (JUNIOR et al., 2008). Casos de osteomielite requerem cuidado minucioso de 
tratamento, sendo recomendada a realização de cultura e antibiograma do material obtido do foco infectado e, subsequentemente, uso de antibioticoterapia adequada para o paciente (RAHAL et al., 2003).

\section{CONCLUSÕES}

O avanço nas pesquisas com células-tronco hematopoiéticas (HSCs) e mesenquimais (MSCs) da MO, em medicina veterinária, desperta a necessidade de aumentar os conhecimentos básicos a respeito de sua origem, sua aquisição e seu processamento. A medula óssea é uma fonte autóloga facilmente acessível de obtenção desse material e pode ser adquirida do interior dos ossos longos, como trocanter maior do fêmur e tuberosidade maior do úmero.

As complicações que podem surgir durante o procedimento de coleta de medula óssea são importantes. Contudo, cuidados como correta orientação da agulha e acurada técnica de introdução da desta podem reduzir significativamente a ocorrência de lesões nos tecidos adjacentes ao foco de coleta.

\section{REFERÊNCIAS}

AQUINO, L.P.C.T. et al. Hematological, biochemical and anatomopathological aspects of the experimental infection with Trypanosoma evansi in dogs. Arquivo Brasileiro de Medicina Veterinária e Zootecnia, v.54, n.1, p.8-18, 2002. Disponível em: <http://www.scielo.br/scielo.php?pid=S0102$09352002000100002 \&$ script $=$ sci_arttext $\&$ tlng $=$ en $>$. Acesso em: 8 mar. 2009. doi: 10.1590/S0102-09352002000100002.

AZEVEDO, W.; RIBEIRO, M.C.C. Fontes de células-tronco hematopoiéticas para transplantes. In: SIMPÓSIO: TRANSPLANTE DE MEDULA ÓSSEA, 2000, Ribeirão Preto, SP. Anais... Ribeirão preto: USP, 2000. V.33, n.4, p.381-389.

BRUNELLI, A.T.J. et al. Transplante autógeno de células-tronco do limbo esclerocorneal em cães. Arquivo Brasileiro de Medicina Veterinária e Zootecnia, Belo Horizonte, v.59, n.5, p.1194-1204, 2007. Disponível em: <http://www.scielo.br/scielo.php?pid=S010209352007000500015\&script=sci_abstract\&tlng=pt $>$. Acesso em: 8 mar. 2009. doi: 10.1590/S0102-09352007000500015.

BRUNO, B. et al. Purified canine CD34+Lin- marrow cells transduced with retroviral vectors give rise to long-term multilineage hematopoiesis. Biology and Blood Marrow Transplantation, Baltimore, v.7, n.10, p.543-551, 2001.

CASTANIA, V.A. Enxerto corticoesponjoso homógeno processado quimicamente, esterilizado em óxido de etileno e embebido em medula óssea autógena. 2007. 67f. Tese (Doutorado em ortopedia. Traumatologia e reabilitação) - Faculdade de Medicina de Ribeirão Preto da Universidade de São Paulo.

CURY, P.M. Biópsia de medula óssea e sua interpretação - o papel do hematopatologista. Revista Brasileira Hematologia e Hemoterapia, Rio de Janeiro, v.2, n.25, p.7980, 2003.
DOMINIS, M. et al. Bone marrow lymphoid aggregates in malignant lymphomas. Croatian Medical Journal, Zagreb, v.3, n.46, p.410-416, 2005.

EL-WARRAK, A.O.; SCHOSSLER, J.E.W. Osteossíntese diafisiária de tíbia em cães mediante inserção intramedular de pinos de steinmann pela crista tibial. Ciência Rural, Santa Maria, v.28, n.1, p.77-82 1998. Disponível em: <http:// www.scielo.br/s cielo.ph p ? p id = S 0103 $84781998000100013 \&$ script $=$ sci_arttext\&tlng $=>$. Acesso em: 8 mar. 2009. doi: 10.1590/S0103-84781998000100013.

FLEURY, S.A. Biópsia de medula óssea (BMO) e sua relação com o aspirado de medula óssea (AMO). 2007. Acessado em 29 jul. 2008. Online. Disponível em: http:// www.fleury.com.br/Publico/LaboratorioReferencia/ ManualHematologia/pages/Bi\%C3\%B3psiademedula\%C3\%B 3sseaBMOesuarela\%C3\%A7\%C3\%A3o.aspx.

GALE, R.P. et al. Aplastic anemia: biology and treatment. Annals of Internal Medicine, Philadelphia, v.95, n.4, p.47794, 1981

GOSSET, K.A. Anemias associated with drugs and chemicals. In: FELDMAN, B.F. et al. Schalm's veterinary hematology. Philadelphia : Lippincott Williams \& Wilkins. 2000. p.185189.

HANS, F.R.D. et al. Melhora sintomática e da capacidade de exercício após o transplante autólogo, transendocárdico, de células mononucleares da medula óssea em pacientes com cardiopatia isquêmica grave, sustentada até o sexto mês de evolução. Arquivos Brasileiros de Cardiologia, Rio de Janeiro, v.84, n.5, p.360-366, 2005.

JAIN, N.C. Evaluation of anemias and polycythemias. In:_____. Essentials of veterinary hematology. Philadelphia: Lea \& Febiger, 1993. Cap.8, p.159-168.

JUNIOR, I.F. et al. Punção e infusão intra-óssea. Acessado em 29 jul. 2008. Online. Disponível em: www.uff.br/ph/artigos/ intraossea.pdf

LARUE, S.M. et al. Biópsia óssea. In: BOJRAB, M.J. Técnicas atuais em cirurgia de pequenos animais. São Paulo: Roca, 2005. Cap. 48, p.794-797.

LOPES, R. et al. Avaliação do hemograma, reticulócitos e mielograma na intoxicação subaguda experimental por aflatoxina em cães. Ciência Rural, Santa Maria, v.28, n.2, p.257-262, 1998. Disponível em: <http://www.scielo.br/scielo.php?pid=S0103$84781998000200013 \&$ script $=$ sci_arttext\&tlng=en $>$. Acesso em 8 mar. 2009. doi: 10.1590/S0103-84781998000200013.

LUND, J.E. Toxicologic effects on blood and bone marrow. In: FELDMAN, B.F. et al. Schalm's veterinary hematology. Philadelphia: Lippincott Williams \& Wilkins, 2000. p.44-50.

MASSUMOTO, C.M.S. et al. Criopreservação de medula óssea e células pluripotentes periféricas utilizando um congelador programável: experiência em 86 congelamentos. Revista Associação Médica Brasileira, São Paulo, v.43, n.2, p.93-98,1997. Disponível em: $<$ http://www.scielo.br/scielo.php?pid=s 0104 423019970002000038\&script=sci_arttext>. Acesso em: 8 mar. 2009. doi: 10.1590/S0104-42301997000200003. 
MENDONÇA, C.L. et al. Avaliação clínica e hematológica em bezerros Nelore infectados experimentalmente com isolados de Babesia bigemina das regiões Sudeste, Nordeste e Norte do Brasil. Pesquisa Veterinária Brasileira, Rio de Janeiro, v.23, n.2, p.52-60, 2003.

NAKAGE, A.P.M. et al. Metodologia e aplicação da citometria de fluxo na hematologia veterinária. Ciência Rural, Santa Maria, v.35, n.4, p.966-973, 2005. Disponível em: <http:// nsdl.org/resource/2200/20061003080541131T>. Acesso em: 8 mar. 2009. doi: 10.1590/S0103-84782005000400040.

NAKAGE, A.M.; SANTANA, A.E. Células-tronco hematopoéticas em cães. Ciência Rural, Santa Maria, v.36, n.1, p.325-329, 2006. Disponível em: <http://www.scielo.br/ s c i e l o.ph p ? s c ri p t = s ci _art t ext \& pid = S 0103 84782006000100054>. Acesso em: 8 mar. 2009. doi: 10.1590/ S0103-84782006000100054

OLIVEIRA, G.K. Células-tronco mononucleares autólogas na cicatrização de defeitos tibiais agudos experimentais de cão. 2008. 50f. Dissertação (Mestrado em Medicina Veterinária) - Universidade Federal de Santa Maria, Santa Maria.

OLSSON, D.C. et al. Aspiração e quantificação da medula óssea em diferentes ossos para transplante de células-tronco mononucleares em cães. In: CICLO DE ATUALIZAÇÃO EM MEDICINA VETERINÁRIA, 12., 2006, Lages, SC. Anais... Lages: Universidade do Estado de Santa Catarina, 2006. V.12. 154p. p.109.

RAHAL, S.C. et al. Osteomyelitis associated with an orthopedic implant. Canadian Veterinary Journal, Ottawa Ontario, v.44, n.7, p.597-599, 2003

RASKIN, R. Medula óssea. In: SLATTER, D. Manual de cirurgia de pequenos animais. São Paulo: Manole, 1998. Cap.64, p.1135-1142.

SALGADO, V.R. Avaliação do cultivo microbiológico de aspirados de medula óssea e sangue no diagnóstico da brucelose canina. Pubvet, Botucatu, v.2, n.24, p.66-71, 2008.

SAMOTO, V.Y. Terapia celular cardíaca: vias de infusão de células mononucleares em cães e gatos srd. 2006 105f. Dissertação (Mestrado em Ciências) - Curso de Pós- graduação em Anatomia dos Animais Domésticos e Silvestres, Faculdade de Medicina Veterinária e Zootecnia da Universidade de São Paulo.

SILVA, R.L.; MACEDO, M.C.M.A. Transplante autólogo de células-tronco hematopoiéticas sem uso de hemocomponentes. Revista Brasileira Hematologia e Hemoterapia, Rio de Janeiro, v.2, n.28, p.153-156, 2006. Disponível em: <http:// www.scielo.br/scielo.php?script $=$ sci_arttext \&pid=S151684842006000200018>. Acesso em: 8 mar. 2009. doi: 10.1590/ S1516-84842006000200018

SILVEIRA, C.D. et al. Stem cell therapy for cardiology: a new path to humanity and a new care for nurses - a case report. Online Brazilian Journal of Nursing (OBJN-ISSN 16764285). Online, 2005 Abr. 4(1). Available in: www.uff.br/nepae/ objn401silveiraetal.htm

SOBRINHO, A.H. et al. Hemograma, mielograma, coagulação sangüínea e teste do nbt na desnutrição infantil. Pediatria, São Paulo, v.1, p.243-248, 1979.

TARVIN, G.B.; LENEHAN, T.M. Tratamento dos deslocamentos sacroilíacos e das fraturas ilíacas. In: BOJRAB, M.J. Técnicas atuais em cirurgia de pequenos animais. São Paulo: Roca, 2005. Cap. 45, p.610-616.

TOGNOLI, G.K. et al. Transplante autólogo de células mononucleares da medula óssea em úlcera de córnea experimental em cães. Ciência Rural, Santa Maria, v.39, n.1, p.148-155, 2009. Disponível em: < http://www.scielo.br/scielo.php?pid=S010384782008005000039\&script $=$ sci_abstract $\&$ tlng=pt $>$. Acesso em: 8 mar. 2009. doi: 10.1590/S0103-84782008005000039.

VAZ, C.E.S. Avaliação do efeito de centrifugado osteogênico de medula óssea na consolidação de fraturas: estudo experimental em coelhos. 2006. 109f. Tese (Doutorado em Ortopedia e Traumatologia) - Faculdade de Medicina da Universidade de São Paulo.

WIJEWARDANA V. et al. Isolation and characterization of hematopoietic progenitor cells in canine bone marrow. Veterinary Immunology Immunopathology, Ireland, v.15, n.3-4, p.230-238, 2007.

ZAMPROGNO, H. Células-tronco esqueléticas para o tratamento da não união de fraturas. Acta Scientiae Veterinariae, Porto Alegre, v.35, n.2, p.289-290, 2007. 